\title{
Editorial
}

\section{Segmental Orthodontics: Simplified approach in Pediatric Orthodontics}

\author{
Vipin Ahuja ${ }^{1, *}$ \\ ${ }^{1}$ Dept. of Pediatric and Preventive Dentistry, Hazaribag College of Dental Sciences and Hospital, Hazaribagh, Jharkhand, \\ India
}

\section{A R T I C L E I N F O}

Article history:

Received 25-10-2021

Accepted 01-11-2021

Available online 12-11-2021
This is an Open Access (OA) journal, and articles are distributed under the terms of the Creative Commons Attribution-NonCommercial-ShareAlike 4.0 License, which allows others to remix, tweak, and build upon the work non-commercially, as long as appropriate credit is given and the new creations are licensed under the identical terms.

For reprints contact: reprint@ipinnovative.com
Pediatric Orthodontics is an indispensable segment of 'Pediatric and Preventive Dentistry' and is practiced in children. It is broadly categorized into preventive and interceptive orthodontics. Preventive orthodontics is practiced to prevent the occurrence of malocclusion and interceptive orthodontics is practiced to prevent the occurrence of malocclusion or to reduce the severity of earnt malocclusion. Early mixed dentition interceptive orthodontics is unanimously practised in children across the globe but is always seen with an eye of qualm and uncertainty. Early orthodontics starting age documented in literature is 7 years, as child is physically and mentally ready for the acceptance of this unique orthodontics. ${ }^{1}$ Early interception either involves full arch or a segment of arch to be treated for malocclusion; and when a segment is used, it is considered as 'Segmental Orthodontics'. 1,2

Segmental Orthodontics is children is advantageous in many ways over full arch orthodontics. It's a simplified approach in pediatric orthodontics as it involves only a segment of few teeth. It is also psychologically acceptable to the growing children and is less time consuming. It is successfully used to treat various incipient and moderate malocclusions of mixed and permanent dentition. The cost incurred is significantly less and is an established management approach in managing varied malocclusions.
Most common early-age malocclusions observed nowadays in practice are single tooth cross-bites and anterior teeth displacements due to mesiodens, other supernumerary teeth or odontomes etc. The treatment protocol used can vary from ' $2 \times 6$ appliance', ' $2 \times 4$ appliance' or 'Brackets on few teeth with NITI approach'. There is a plethora of literature to support the fact that early interception of malocclusion in mixed dentition is of utmost importance and should be dealt on priority. ${ }^{3}$ It's a well proved fact that treatment of crossbite is a dental emergency and should be treated at the age it is seen. Henry and Post ${ }^{4}$ stated that early removal of mesiodens in early mixed dentition is a necessity to promote eruption and proper alignment of adjacent teeth, which may reduce the need for orthodontic treatment. It was further observed that delayed extraction of the mesiodens after the age of 10 when the apex of the central incisor nearly forms may require more complex surgical and orthodontic treatment for correcting the malocclusion. Therefore, it is imperative to intercept certain malocclusions at an early age. The Pediatric dentist is a specialized dentist who come across these young malocclusions at a very young age and should have a sound clinical knowledge to diagnose and correct these malalignments with the simple protocols like segmental orthodontics in pediatric dentistry.

\footnotetext{
* Corresponding author.

E-mail address: drvipinahuja@gmail.com (V. Ahuja).
} 


\section{Conflict of Interest}

The authors declare that there are no conflicts of interest in this paper.

\section{References}

1. Verma J, Ahuja V. Interception of developing anterior malocclusion due to supernumerary tooth by " 2 x 4 Appliance": A clinical case report. $J$ Dent Panacea. 2021;3(1):40-5.

2. Agarwal A, Mathur R. Segmental Orthodontics for the Correction of Cross Bites. Int J Clin Ped Dent. 2011;4(1):43-7.

3. Henry RJ. A C Post A labially positioned mesiodens: case report. Pediatr Dent. 1989;11(1):59-63.

4. Sharma DS, Kambalimath. NB Reddy Management of Developing Anterior Malocclusion due to Supernumerary Tooth with Preventive and Interceptive Approach: A $1 \frac{1}{2}$ Year Case Study. Int J Clin Pediatr Dent. 2010;3(2):107-10.

\section{Author biography}

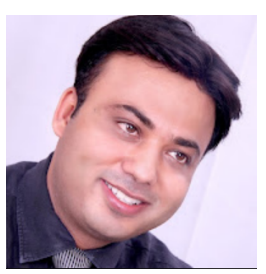

Vipin Ahuja, Professor \& Head, Hazaribag College of Dental Sciences and Hospital, Hazaribagh, Jharkhand, India

Cite this article: Ahuja V. Segmental Orthodontics: Simplified approach in Pediatric Orthodontics. J Dent Panacea 2021;3(3):97-98. 